\title{
LOS COMENDADORES DE CÓRDOBA, DE LOPE, DESDE LA AGNICIÓN Y EL SIMBOLISMO
}

\author{
Ismael López Martín \\ Universidad de Zaragoza
}

\section{Resumen}

El propósito de este trabajo es analizar el tratamiento de la agnición y del simbolismo en una de las obras más destacadas de Lope de Vega de finales del siglo xvi: Los comendadores de Córdoba. Con su presencia permiten desencadenar importantes cambios en la acción, fundiéndose en los incidentes climáticos de la obra y facilitando un mejor conocimiento de las motivaciones que los agonistas tienen a la hora de desempeñar su función en la pieza y de desarrollar los dos grandes ejes temáticos que enmarcan la obra: el amor en sus distintas realizaciones y el honor. La sucesión intermitente de estos mecanismos en distintos puntos de la obra implica que el lector y el espectador sean avisados de que la relevancia del elemento al que hace referencia es fundamental para el desarrollo de la acción de la comedia y para la resolución de los conflictos.

Palabras clave: Teatro barroco, Lope de Vega, Los comendadores de Córdoba, agnición, simbolismo.

\section{LOS COMENDADORES DE CÓRDOBA, BY LOPE, FROM AGNITION AND SYMBOLISM}

\begin{abstract}
The aim of this paper is to analyze the treatment of agnition and symbolism in one of the most important plays written by Lope de Vega in the late 16th century: Los comendadores de Córdoba. With their sole presence they allow the action to experiment important changes, either by sinking in the climatic incidents of the play or by facilitating a better knowledge of the motivations that the characters have in the performance of their function and in the development of the two major thematic axes that frame the work: love in its various achievements and honor. The intermittent succession of these mechanisms in different moments of the play makes the reader and the audience be warned about the relevance of the element for the development of the action in the comedy and for the resolution of the conflicts.

Keywords: Baroque theater, Lope deVega, Los comendadores de Córdoba, agnition, symbolism.
\end{abstract}


Lope, después de su paso por Valencia (donde entró en contacto con Guillén de Castro, Gaspar Aguilar, Ricardo de Turia o Andrés Rey de Artieda, miembros de la popularísima Academia de los Nocturnos) y Toledo (lugar en el que asistió a don Francisco de Rivera y Barroso) ${ }^{1}$, hacia 1590 entró al servicio del v duque de Alba, don Antonio Álvarez de Toledo y Beaumont, que, como Lope, estaba desterrado. En 1595 falleció su esposa, Isabel de Urbina, y abandonó la casa del duque para trasladarse a Madrid, pues su pena ya había expirado gracias a un indulto (Castro y Rennert, 1969: 97).

En 1596, año de composición de Los comendadores de Córdoba (Morley y Bruerton, 1947: 57), muere Teodora, la segunda hija que Lope tuvo con Isabel de Urbina (Castro y Rennert, 1969: 100). Además, en ese año fue procesado por amancebarse con la viuda Antonia Trillo de Armenta ${ }^{2}$. En 1598, por otro lado, entra al servicio de don Fernando Ruiz de Castro Andrade y Portugal, iii marqués de Sarria y vi conde de Lemos, y contrae matrimonio con doña Juana de Guardo.

Los acontecimientos que aparecen en Los comendadores de Córdoba tienen su correlato histórico en un episodio acaecido en dicha ciudad hacia 1448, durante el reinado de Juan II de Castilla ${ }^{3}$, en el que el Veinticuatro don Fernando Alfonso de Córdoba mató a su mujer, doña Beatriz de Hinestrosa, a los comendadores don Jorge y don Fernando Fernández de Córdoba y Solier y a criados de su casa para restablecer la honra que habia perdido. Fue indultado al año siguiente merced a un privilegio real. Más allá del componente histórico, los hechos pronto pasaron a la literatura, en concreto a la composición que comienza "¡O cama de nuevos de ver girifaltes!"

${ }^{1}$ En 1590 don Francisco de Rivera y Barroso era un caballero perteneciente a una casa noble, pero no poseía ningún título, ya que su padre, don Pedro Barroso de Rivera y Figueroa, aún mantenía los títulos de señor de Malpica y de Parla, entre otros. Fue en 1599 cuando Felipe III otorgó el marquesado de Malpica a don Pedro, que fue su primer titular, a quien sucedió su hijo en fecha que desconocemos. Don Francisco de Rivera y Barroso sería el ii marqués de Malpica, pero en el momento en que Lope de Vega le sirvió como criado no lo era, y nunca Lope sirvió al marqués de Malpica, porque el título se creó casi diez años después, cuando élya servía al iii marqués de Sarria y vi conde de Lemos. Los documentos que prueban la vinculación del Fénix con Rivera en torno a 1590 fueron publicados por García Rey (1928: 198-205). Adviértase, así, el error de Castro y Rennert (1969: 110), que sostenian que sirvió al marqués de Malpica (incluso sin haberse creado el título) a partir de 1596, tras el servicio de nuestro dramaturgo al v duque de Alba.

${ }^{2}$ Lope dedicó un soneto a Antonia Trillo que se conserva en diversas fuentes con variantes (Vega Carpio, 1993-1994, i: 477), como explica Pedraza en su edición de las Rimas. Precisamente una de esas versiones es la incluida por el Fénix, en boca de don Fernando, al final de la primera jornada de Los comendadores de Córdoba, entre los versos 906 y 919 (Vega Carpio, 1998: 1077-1078).

${ }^{3}$ La comedia del Fénix está ambientada en el reinado de Fernando el Católico, al final de la conquista del reino de Granada, en 1492. 
del Cancionero de Antón de Montoro. Pero también aparecieron numerosas versiones de las "Coplas de los Comendadores", ya más populares, que se incluyeron en obras de los más variados géneros y autores. Sin embargo, fue del denominado "Romance de los Comendadores", incluido por Juan Rufo en Las seiscientas apotegmas y otras obras en verso en 1596, de donde la comedia lopesca, que se publicó por primera vez impresa en la Segunda parte de las comedias de Lope de Vega Carpio (Madrid, Alonso Martín, 1610), bebió fundamentalmente ${ }^{4}$.

Los comendadores de Córdoba es una sangrienta tragedia lopesca de doble acción, ambas convergentes al final de la pieza. La primera de ellas es la que afecta a la vida personal y social del Veinticuatro y a las relaciones amorosas y honrosas con su esposa y miembros de su casa. La segunda se vincula a los hechos históricos de la conquista de Granada y a la vida palaciega y nobiliaria del rey Fernando el Católico y de su corte. En ambas, el tema de la honra del protagonista es fundamental, pero a lo largo de las siguientes páginas nos centraremos en la primera acción. Es ahí donde el honor corre parejo al amor y a las relaciones entre personajes, que en las múltiples realizaciones que presentan sirve para plantear y desarrollar el conflicto de honor. Pero, además, se advierten dos procedimientos que contribuyen notablemente a reforzar el tema del amor y del honor, la agnición y el simbolismo, que permiten generar las mayores situaciones de tensión dramática de la obra, los incidentes climáticos, y plantear una evolución hacia una cruenta restitución de la honra a través, según Costa Palacios y Abad Gómez (1981: 142), de una fórmula que podría acomodarse a las tragedias tremendistas.

\section{La simbiosis temática: el honor y las relaciones personales}

El honor es el tema sobre el que giran los acontecimientos de Los comendadores de Córdoba, tal y como apreció Cañas Murillo (1995: 31). Pero no es menos cierto que cuando el personaje protagonista, el Veinticuatro, intenta recobrar la honra perdida lo hace porque ha sufrido una serie de consecuencias a partir del tema del amor, que una vez más se antoja indispensable en la comedia nueva barroca como elemento simbiótico del binomio amor-honor; uno y otro se interrelacionan de tal manera que a veces se hace muy difícil separarlos o, incluso, inferir la causa de cada uno de ellos. En palabras de Rozas (1976: 144): "amor y honra eran los grandes revulsivos de las comedias del siglo xvii».

${ }^{4}$ Los orígenes y fuentes de esta obra están convenientemente estudiados, entre otros, por Menéndez Pelayo (1949, v: 250-269), Stroud (1981: 425-426), Rey Hazas (1991: 413-414) y Laplana Gil en su edición de la comedia (Vega Carpio, 1998: 1027-1032). Sobre la historia textual véanse Vega Carpio (1998: 1034-1045) y Laplana (1999: 197-198). 
En el caso de la citada comedia de Lope podemos advertir tres tipos de relaciones interpersonales en función no tanto de los personajes que intervengan en ellas, sino, precisamente, de la naturaleza de esos vínculos. Así, mencionaremos la admiración vasallática, el aprecio personal y el amor de pareja.

El principal valedor de la admiración vasallática, que también podríamos denominar señorial, es el personaje del rey Fernando el Católico, que interviene en la segunda acción de la pieza y sirve de unión con la primera, aunque en menor grado que el protagonista, como veremos a continuación. E1 rey es un personaje que está construido sobre el tipo cómico del poderoso, y como tal ejerce su función de dominio positivo con respecto a sus vasallos y cortesanos, muy especialmente en el contexto de la guerra de Granada. El rey valora notablemente el valor y la honra, y por eso está rodeado de otros nobles y soldados como Garcilaso de la Vega (a quien Lope aprovecha para rendir homenaje por su mérito literario), el conde de Palma, Hernando del Pulgar y don García de Toledo. El rey se encarga de ensalzar las virtudes de todos, especialmente reconocidas a partir de la toma del reino nazarí; con todos departe en consejo, lo que permite situaciones de confianzay de respeto al amparo de esa admiración que hemos venido en llamar vasallática porque, al final, hay un señor y un vasallo en la relación.

El vínculo que mantiene el rey Fernando con el Veinticuatro de Córdoba, con el que comparte el nombre de pila, es mucho más estrecho como para estar estigmatizado por los parámetros de amo y vasallo. El protagonista de la comedia guarda con el rey una relación tan positiva que supera, incluso, a la que mantiene con su esposa, muy especialmente hacia el final de la obra. Ambos podrian llamarse amigos, y como tal el rey se permite aconsejar a su siervo en los asuntos de su honor personal relacionados con la fidelidad de su mujer, adquiriendo el monarca, así, ciertas características del tipo cómico del criado, de quien son propias las funciones de confidente y consejero. Cuando celebra audiencias, el rey recibe el último al Veinticuatro, y expresa un sentimiento de especial alegría cuando ve a su amigo. El vínculo no es menos claro en sentido opuesto, ya que el Veinticuatro sigue los consejos del rey y acude ante él cuando culmina su venganza para que lo mate con su propia espada, impartiendo, así, justicia; el Veinticuatro reconoce solo en el rey a quien puede quitarle la vida si lo desea. Sin embargo, es al final de la comedia cuando la relación entre ambos se refuerza hasta sus máximos niveles, pues el monarca otorga el perdón real al marido desagraviado porque se entiende que ha sido un "hecho famoso y notable" (Vega Carpio, 1998: 1139). Como explica Escudero Baztán (2014: 12), desde esa perspectiva "la magnitud del castigo recibido guarda proporción a la afrenta". Además, para aliviar su desazón amorosa le otorga a doña Constanza de Haro como esposa en segundas nupcias, que ya se celebrarian en la posthistoria de la comedia. 
El segundo tipo de relación que observamos en Los comendadores de Córdoba es el aprecio personal, que nos permite englobar los lazos familiares y los de servidumbre.

Los parentescos en la obra se desarrollan, fundamentalmente, a partir de la pareja protagonista, el Veinticuatro y doña Beatriz; así, aparecen los siguientes: doña Ana es la sobrina del Veinticuatro; los amantes de ambas damas, don Jorge y don Fernando, son hermanos, y sobrinos del obispo de la ciudad; pero además, los dos comendadores son primos del Veinticuatro. Las relaciones familiares son muy variadas. Veamos algunas de sus características.

En primer lugar, el parentesco de tío y sobrina del Veinticuatro con doña Ana aporta una relación positiva, serena y feliz; ambos viven en la misma casa y la relación evoca una protección paternal de don Fernando Alfonso hacia su sobrina.

Los dos comendadores, don Jorge y don Fernando, son hermanos, y ambos mantienen una relación de confianza que permite establecer un paralelismo entre los dos, pues cumplen funciones muy semejantes en función de su procedencia (son sobrinos del obispo de Córdoba, que es citado en la comedia, pero no interviene), de su rango (son comendadores de una orden militar), intereses (llegar a la casa de su primo, el Veinticuatro, y ser amantes de dos damas) y destino (morirán a manos del protagonista habiendo experimentado diferentes agüeros premonitorios, que se explican más adelante). Sin embargo, por situarse junto a la esposa del protagonista, el personaje de don Jorge es de mayor relevancia en la pieza que el de don Fernando.

Por último, cabe decir que la relación que se establece entre el Veinticuatro y sus primos, los comendadores, es la más compleja de todas, ya que maneja conceptos como la hipocresía o el engaño y experimenta una evolución a lo largo de la comedia ${ }^{5}$. En un primer momento, el vínculo por parte del Veinticuatro está basado en la confianza y serenidad que otorga una relación familiar, en clara correspondencia con la que mantiene con doña Ana. Por su parte, los comendadores son hipócritas porque se comportan con tranquilidad con el Veinticuatro, siendo gentiles, ofreciéndose a acompañarle de caza o alabando sus virtudes. Sin embargo, en realidad temen que descubra el engaño que están llevando a cabo mediante el cual se sostienen relaciones amorosas con su esposa y sobrina en su casa. Es un juego de equilibrios en el que el más mínimo detalle puede derrumbar toda

${ }^{5}$ También hay evolución entre la relación que mantienen los comendadores con un amigo suyo, el caballero don Luis, un personaje secundario que se sitúa al lado de los hermanos en un primer momentoy que, por falta de apoyo en un incidente, retira su amistad más adelante. 
la situación, como así sucede con los casos de simbolismo, que se detallan más adelante. El público está al corriente de toda la situación. Cuando la obra y la relación evolucionan, una vez que el Veinticuatro ha sido destinatario de la anagnórisis sobre la verdad que acaecía en su hogar, es él quien, ahora, planea comedidamente su venganza y oculta a los comendadores sus verdaderas intenciones. El culmen de la evolución será el asesinato de los hermanos por parte del Veinticuatro para recuperar su honra.

Además de las familiares, las relaciones que se establecen en torno a la servidumbre son también muy interesantes. Nuevamente circundan la pareja principal, aunque las que se entablan ahora son mucho más ricas y responden a parámetros como la simetría, la traslación y el paralelismo de amos y señores en sus relaciones de pareja. Así, las damas de la casa del Veinticuatro tienen a Antonia como doncella y a Esperanza como esclava. Doña Beatriz comparte con el Veinticuatro su dominio sobre el criado Medrano, pero es el protagonista el único que tiene un criado a su servicio en exclusiva, el esclavo Rodrigo. Los comendadores comparten lacayo, Galindo. No son destacables las relaciones que mantienen los personajes con Antonia ni con Medrano, pero sí el resto.

En primer lugar destacaremos que doña Beatriz y doña Ana, las dos damas de la casa del Veinticuatro, mantienen relación con la esclava Esperanza, que también vive con ellas. En este caso, los tres personajes deciden apoyarse mutuamente en el adulterio y en permitir al grupo de los comendadores y su lacayo que entren en su casa y alcoba cuando el Veinticuatro no está presente por encontrarse de viaje. Las tres están perfectamente conectadas y establecen un paralelismo en sus relaciones de pareja.

Pero es que con los comendadores sucede algo parecido. Los dos tienen un lacayo, Galindo, que es su confidente y consejero, puesto que está construido sobre el tipo del criado. Los tres entran en la casa del Veinticuatro y cada uno se va con su pareja, de tal manera que doña Beatriz mantiene una relación adúltera con don Jorge, doña Ana con don Fernando (en este caso es una relación normal, porque la dama no está casada ni tiene otro pretendiente) y Esperanza con Galindo (esta sí tiene otro criado que la corteja, el del Veinticuatro), en una relación que anota el punto cómico con respecto a los escarceos de sus señores.

Por último, el Veinticuatro, protagonista de la comedia, es el único personaje que tiene a un criado, Rodrigo, en exclusiva, y precisamente es uno de los más fieles con respecto a su señor. La confianza entre ambos es total; el esclavo avisa a su señor de lo que ocurría en su casa durante su ausencia y colabora con élen la matanza que llevará a cabo al final de la obra, aunque no parece que lo haga por proteger la honra de su amo, sino por celos e 


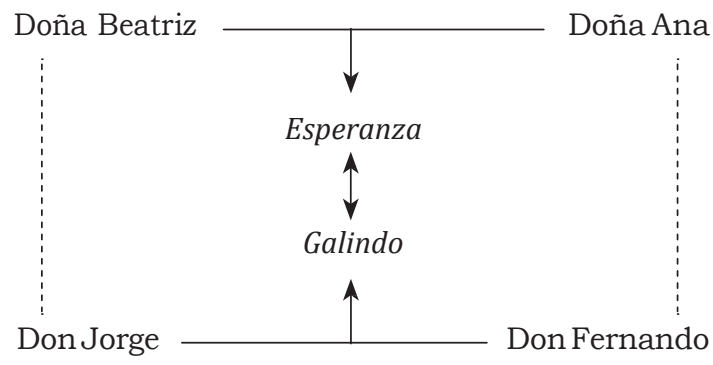

Fig. 1.

interés, el interés por recuperar a Esperanza (a quien pretendia) y alejarla de Galindo, el lacayo de los comendadores.

El amor de pareja es el tercer tipo de relación que se establece entre los personajes. Son vínculos marcados por el tradicional y efectivo recurso del triángulo amoroso más allá de consideraciones morales como las que se derivarian del honor y del adulterio de doña Beatriz. Unas y otras tienen diferencias sustanciales de base, pero sobre todo debemos advertir la evolución que experimenta una de ellas a lo largo de la comedia. Estas relaciones son las más importantes de la obra porque son las que permiten que se desarrollen todos los conflictos y se acuda a los recursos de la anagnórisis y del simbolismo, entre otros, para solucionarlos; por ello las protagonizan los agonistas principales y sus correlatos en forma de criados. Existen relaciones entre el Veinticuatro y su esposa, entre esta y don Jorge, entre doña Ana y don Fernando y entre los criados Rodrigo y Esperanza y esta y Galindo.

La relación más importante es la que entabla la pareja protagonista: el Veinticuatro de Córdoba y doña Beatriz. Pueden distinguirse dos momentos en su evolución, marcados por la agnición del galán. Así, en un primer momento doña Beatriz lamenta el encierro que sufre debido a la ausencia celosa del marido y, cuando este llega a casa después de participar en la segunda acción de la comedia, lo saluda y finge celos y un amor que ya su esposo intuye que manifiesta de una forma exagerada ("dejad ya tantos excesos", Vega Carpio, 1998: 1074). Por su parte, el Veinticuatro es más prosaico y, además, Lope intenta dotarlo de características positivas que justifiquen su posterior venganza; se atreve, incluso, a poner en su boca excursos o disquisiciones sobre las obligaciones del matrimonio, elogiando la vida de casado y la condición de su esposa. Es confiado, gentil y atento con ella, y le regala el anillo que le había entregado el rey Fernando como prueba de su estima, cuyo simbolismo se detallará más adelante. Además, el Veinticuatro elogia las virtudes de los comendadores y llega a decir "en tales manos cayese / siempre mi honor» (Vega Carpio, 1998: 1085), a lo que 
doña Beatriz responde en aparte "(Ya lo está)", afirmando y reconociendo que es adúltera y que ha hecho que su marido haya perdido el honor. En la segunda parte de esa relación, cuando el Veinticuatro ya está desengañado y conoce la verdad sobre su deshonra, no echa la culpa al matrimonio, que es un asunto divino sobre el que no había escatimado en elogios previamente, sino que centra su ira en las mujeres, pero no parece que generalice su misoginia, sino que asume que las hay buenas y malas, y él se había casado con una de las segundas, simplemente. Por parte de doña Beatriz no cambia la situación, sigue intentando ocultar su romance, pero es cierto que el Fénix se centra en el conflicto introspectivo del Veinticuatro, en su venganza y en ciertas dosis de teoría sobre el amor y la honra. Ambos sostienen, por tanto, una relación complejay turbulenta.

A lo largo de toda la comedia aparece el amante y el recurso del triángulo amoroso. El comendador don Jorge, primo del Veinticuatro, entra en su casa y mantiene una relación incestuosa con doña Beatriz, mujer casada a la que le preocupa más su amante que el honor de su esposo, por lo que no incide en el problema de amor y honor como hace el Veinticuatro, ella elige claramente el amor y su deseo personal, tal y como señala Álvarez Sellers (1997: 605). La dama adúltera justifica su comportamiento por las ausencias de su marido y una falta de correspondencia amorosa entre ambos, como ya se ha visto (Fernández, 1986: 57). Conscientes de que la relación de amantes que mantienen es inadecuada, la ocultan al Veinticuatro, pero no a los criados de la casa ni a los otros personajes que viven en el mismo lugar, también implicados. Interesa especialmente el anillo, símbolo de aprecio que el rey había dado al Veinticuatro, este a su esposa y ella, ahora, sin desvirtuar del todo su significado, a su amante don Jorge, lo que permitirá al protagonista conocer la verdad.

Para el desarrollo del conflicto de los protagonistas la relación entre doña Ana y el comendador don Fernando, hermano de don Jorge, no tiene mucha relevancia, más allá de que forma un paralelismo con la relación extramatrimonial de doña Beatriz con don Jorge y de que el Veinticuatro entiende que se mancilla el honor de su casa porque él no ha permitido que se mantengan tantas relaciones en su hogar. Pero hay una diferencia fundamental, y es que doña Beatriz está casada y doña Ana no, ni tampoco está prometida ni tiene otro pretendiente que la requiebre en amores; es absolutamente libre.

Más allá de los amos, los criados también ofrecen su particular visión de lo que acontece en la casa del Veinticuatro, aunque con más comicidad. Rodrigo, criado de don Fernando Alfonso, quiere acercarse a Esperanza, criada de doña Beatriz y de doña Ana, y esta le rechaza en varias ocasiones, aunque sí consiente a Galindo, el lacayo de los comendadores. Rodrigo es 
el personaje celoso de la comedia por excelencia, pues ve que la habitual traslación de amores entre amos y criados queda turbada por la presencia de Galindo, amante como los comendadores. Rodrigo actúa por celos y colabora con el Veinticuatro en la revelación de la verdad y en la venganza más por despecho que por fidelidad a su amo, quien, sin embargo, no actúa por ese motivo a pesar de estar casado y haber sido engañado, sino por honor.

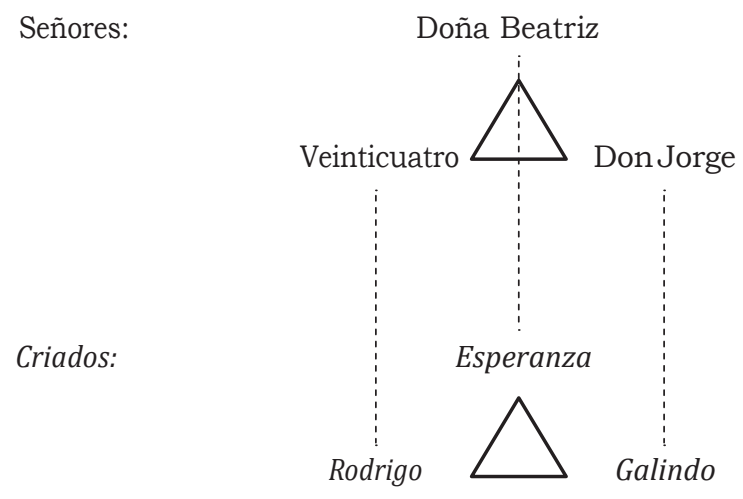

Fig. 2.

Para concluir con este apartado, precisamente a raíz de su venganza el Veinticuatro emergerá casi como un deus ex machina ("bajando por arriba del teatro", dice la acotación, Vega Carpio, 1998: 1131) para impartir justicia ante los vituperios que ha sufrido su casa; y lo hará en forma de asesinato de todos los personajes y animales que hay en el lugar (salvo su criado Rodrigo) en lo que es un nuevo modo de relación entre personajes: el Veinticuatro es el verdugo de todos ellos. Lo que a priori es una justicia o una venganza desproporcionada, como sucede, por ejemplo en La serrana de La Vera, otra comedia de Lope, en ambos casos queda ratificada por la instancia superior que es el rey, quien otorga el perdón real, como en Fuente Ovejuna.

2. El punto de inflexión hacia el final de la comedia: la agnición

El recurso de la anagnórisis supone el proceso mediante el cual determinados personajes acceden a la verdadera identidad o naturaleza de otro agonista, de un hecho o de un símbolo, de tal manera que la acción puede cambiar sustancialmente cuando este procedimiento aparece en la comedia. La agnición fue muy utilizada por Lope de Vega en sus comedias, y puede encontrarse en situaciones de todo tipo y en comedias de todo género. 
Parece claro que no todas las anagnórisis tienen la misma importancia en una obra, y la relevancia procederá del grado en que la acción de la pieza varie. En Los comendadores de Córdoba pueden distinguirse tres grandes anagnórisis, además de otras conversaciones en las que el intercambio de información sea únicamente la finalidad de ese diálogo, circunstancia que no nos permitiría situar el incidente en la categoría de agnición. Así, estas tres anagnórisis se sitúan al final de la primera jornada (vv. 927-930), al final de la segunda (vv. 1921-1927) y a la mitad de la tercera (vv. 2401-2015). La primera agnición no parece tener mucha relevancia para el desarrollo de la comedia, tiene consecuencias anticlimáticas, y en ella don Jorge y don Fernando, comendadores de Córdoba, solo se reconocen mutuamente antes de darse a cuchilladas. Se trata de una anagnórisis en la que se descubren las identidades de los personajes que intervienen en ella, que son dos, y además los dos principales. El descubrimiento se realiza a través de la mera conversación, por lo que predomina la oralidad. El público, por su parte, no desempeña una función relevante, y eso que el Fénix generalmente daba a los espectadores toda la información de antemano, de tal manera que se convertía en un auditorio omnisciente. A nivel de la versificación, Lope utiliza la redondilla en este reconocimiento, la estrofa más empleada en las agniciones de su teatro ${ }^{6}$.

Sin embargo, las otras dos agniciones ya sí que intervienen de modo decisivo en el devenir de la acción. En la primera de ellas, la situada al final del acto segundo, el Veinticuatro ve en poder de don Jorge el anillo que el rey Fernando el Católico le había regalado a él y este a su mujer, y de ese modo infiere que su esposa le es infiel. La segunda, situada hacia la mitad delúltimo acto, es aquella en la que el criado Rodrigo revela al Veinticuatro toda la verdad sobre lo que acontecía en su casa durante su ausencia, muy especialmente las relaciones amorosas que allí se producian, incluidas las de su mujer, doña Beatriz. Las sospechas que tenía don Fernando Alfonso desde que vio el anillo en la mano de don Jorge se confirman y empieza a planear su venganza. Como se ha explicado previamente, no parece que Rodrigo cuente la verdad a su amo por lealtad, sino más bien por despecho, empujado por los celos que tenía de Esperanza, que compartía lecho con el lacayo de los comendadores, Galindo.

Lope utilizaba algunos componentes escenográficos que potenciaban la efectividad de las anagnórisis en sus comedias: el disfraz, el cambio de nombre (o ambos a la vez), la mutación o el empleo de un elemento del decorado o del vestuario. Los primeros son los más numerosos, pero las dos

${ }^{6}$ Laplana Gil sistematizó la versificación utilizada por el Fénix en Los comendadores de Córdoba en su edición de la obra (Vega Carpio, 1998: 1049). 
agniciones que nos ocupan están producidas por elementos complementarios que los personajes pueden llevar encima: el anillo y la carta. Como se ha dicho antes, el Fénix solía informar al público de todo, y cuando estos reconocimientos se producen los espectadores ya son conocedores de la verdad, pues las relaciones se han mantenido a la vista de todos (salvo del Veinticuatro) desde el inicio de la comedia.

Las estrofas más empleadas en las anagnórisis son la redondilla (utilizado para la primera agnición de Los comendadores de Córdoba que se ha explicado, aquella que no poseía relevancia para la acción) y el romance; sin embargo, las dos anagnórisis en las que ahora nos centramos están escritas en décimas, la primera, y en endecasílabos sueltos, la segunda. Lope ya defendió la polimetría en su Arte nuevo; se trata por tanto, de "acomodar el estilo, en este caso la métrica, a los temas" (Rozas, 1976: 122).

La agnición del final de la segunda jornada de la comedia es simbólica según su objeto (pues se reconoce el propio anillo), no verbal por símbolos en virtud del procedimiento (ya que contribuye a la revelación a través de la simbología que desarrolla dicho elemento) e intencional por cambio en la actitud según sus consecuencias (la anagnórisis provoca que el Veinticuatro ahora intuya o casi sepa la verdad sobre lo acontecido en su casa a través de la sortija y cambie su comportamiento hacia su esposa: ahora no será tan condescendiente y procederá a llevar a cabo la venganza).

En cuanto al otro reconocimiento que se cita, el que se produce en el ecuador del último acto, puede clasificarse como incidental de incidente real según el objeto (son los propios hechos o incidentes que han tenido lugar verdaderamente en la casa los que se reconocen), verbal escrita según su procedimiento (es a través de la carta que lee el personaje como llega a la confirmación de los sucesos, aunque se atempera con el diálogo posterior entre el Veinticuatro y su criado Rodrigo) y climática por fallecimiento en función de las consecuencias (el resultado de la revelación es que el protagonista pone en marcha su venganza y acaba con la vida de todos los que había en su casa salvo él mismo y su esclavo).

Aunque la violencia o muertes ingentes ${ }^{7}$ de esta obra coinciden con las de La serrana de La Vera de Lope, el punto de partida es distinto: la serrana mata a los hombres solo por el hecho de serlo, el Veinticuatro mata a todos los que encuentra, sin ninguna otra particularidad, es más, mata a todos aunque no hayan contribuido a la infidelidad de su mujer.

${ }^{7}$ Menéndez Pelayo (1949, v: 270) ya explicó que Lope no quiso atenuar el mal comportamiento de los personajes que mueren a manos del Veinticuatro, justificándose también, desde el punto de vista del público, la venganza. 
Ni el Veinticuatro ni Leonarda (de La serrana de La Vera) son personajes negativos al comienzo de sendas obras; todo el sufrimiento que provocan 8 tiene su origen en el fracaso de sus relaciones amorosas, bien por celos (en La serrana de La Vera), bien por deshonra (en Los comendadores de Córdoba). Esos conflictos internos justifican las matanzas, y por eso ambos reciben el perdón del propio rey.

Al final de la obra, las muertes provocadas por el Veinticuatro se producen entre bambalinas. Ya Horacio recomendaba que no se produjeran muertes ante el público, sino que se sustituyeran por parlamentos elocuentes sobre el particular. El propio Álvaro Cubillo de Aragón, dramaturgo barroco español, admitió en su obra El enano de las musas que esa práctica no podía adscribirse al buen gusto (López Martín, 2014: 42-45).

\section{Los objetos que cambian el curso de la acción: el simbolismo}

El simbolismo es un recurso de composición que aparece en multitud de comedias de Lope de Vega y de otros autores del teatro áureo español y que, además, está muy presente en algunos tipos de agnición. Supone la adquisición de un significado especial y reiterativo a lo largo de la comedia para unos elementos físicos u objetos que se identifican con valores morales, jurídicos, políticos, con personajes o con incidentes de la acción. Ligado con la anagnórisis aparece en comedias lopescas como La reina Juana de Nápoles, El postrer godo de España o Los comendadores de Córdoba.

A lo largo de la pieza que analizamos en estas páginas aparecen distintos simbolos, cada uno con su significado. Sin embargo, no todos poseen la misma importancia para el desarrollo de la acción. De hecho, aquellos que están relacionados con la anagnórisis y el clímax son los más destacados, los más recurrentes durante toda la obra y a los que Lope dedica más explicaciones, puesto que su significado es crucial para la resolución del conflicto dramático.

En primer lugar citaremos el origen social elevado del que proceden los dos comendadores, don Jorge y don Fernando, que lucen en su pecho la cruz de la orden militar a la que pertenecen sus encomiendas. Estas cruces otorgan honor y posición a quien las lleva, y a menudo eran símbolo de la hidalguía de quienes las ostentaban. Al comienzo de la obra alaba don Luis a sus amigos los comendadores, quienes presentan "por buena sangre, las cruces, / por obras, las encomiendas" (Vega Carpio, 1998: 1053).

${ }^{8}$ Como explica Oleza (1986: 260), se produce la "transformación de la víctima en verdugo, y de los agresores en víctimas". 
Ya en la tercera jornada el criado Rodrigo le dice al Veinticuatro, su amo, que lea la carta que le ofrece (versos 2403-2405). La trasmisión de información a través de cartas, papeles o billetes en las comedias es un recurso muy empleado, y simboliza la incuestionabilidad de la palabra escrita como fuente de verdad. En Los comendadores de Córdoba aparece una carta asociada a una agnición, pues es en aquella en la que se recogen los amores adúlteros de la esposa del protagonista y los desatinos que se producen en su casa durante su ausencia.

Hacia la mitad de la tercera jornada, justo después de la lectura de dicha carta, se produce otra asociación simbólica, la que se refiere a que "la honra se derrama como el agua..." (Vega Carpio, 1998: 1122), como ya señaló Álvarez Sellers (1997: 600). Así, el Veinticuatro dará de beber agua a don Jorge (v. 2443), a don Fernando (vv. 2448-2449) y al lacayo Galindo (v. 2526), que simboliza cómo ellos se han bebido su honra. Es el comienzo de su venganza.

Al final de la comedia, el Veinticuatro presenta al rey Fernando la espada con la que había matado a los que habitaban en su casa como venganza para recuperar la honra. La pone a disposición del monarca entre los versos 2991 y 2993 para que lo decapite con la misma arma con la que él se había vengado. La espada es, aquí, símbolo de la justicia. Para Ebersole (1983: 62) es precisamente el relato ante el rey el hecho que hace público que el Veinticuatro ha perdido valor personal, al efectuar esa matanza, por haber defendido su derecho a la honra y su restitución sobre todo lo demás. En cualquier caso, lavenganza que hallevado a cabo es, para el protagonista, "a process of earthly salvation" (Larson, 1971: 406).

Pero sin lugar a dudas, como señaló Rey Hazas (1995: 307-309), el simbolismo de mayor trascendencia para el desarrollo de la acción de la comedia lo concita el anillo. En la obra, esta sortija es un objeto que aparece desde el principio hasta el final y el público sabe que tiene unas propiedades que lo diferencian de cualquier otro objeto. La primera vez que aparece esta joya es poco antes de la mitad del primer acto. El rey Fernando el Católico, como prueba de su reconocimiento hacia el Veinticuatro, le entrega el objeto ("vete a ver tu casa, y lleva / este anillo de mi mano" (Vega Carpio, 1998: 1063). El Veinticuatro realiza un monólogo justo después en el que reivindica la modestia de sus acciones y pide al monarca que dé tan prestigiosa y simbólica joya a otros caballeros de su corte, más valerosos. Al final acepta el regalo y don Fernando Alfonso asume su importancia, basada en la confianza del rey, su señor. Precisamente el hecho de que el dramaturgo dedique tantos versos a este pasaje de la comedia hace que el anillo adquiera una simbología particular y que permanezca en la mente del auditorio para cuando, más adelante, sea necesario. 
Más tarde, al iniciarse la segunda jornada, el Veinticuatro y su esposa, doña Beatriz, deben separarse de nuevo. Como prueba de estima y amor, y para que lo conserve en su recuerdo, el marido entrega a su mujer el anillo que le había regalado el rey. Nuevamente esta sortija cambia de manos en una despedida y el Veinticuatro glosa lo que significa la joya para él mientras se lo da a doña Beatriz. La esposa lo toma, aunque se muestra menos agradecida que el Veinticuatro cuando este lo recibió por primera vez y menos emocionada que quien se lo entrega, que lo cree prueba de todo lo que le pertenece.

Pero la joya vuelve a cambiar de manos. Avanzada la segunda jornada, cuando doña Beatriz, actual poseedora, va a separarse de su amante, el comendador don Jorge, ella recurre a la sortija para entregarle su prueba de amor y recuerdo para la partida.

Como se ve, aunque el anillo cambia de dueño, los valores que adquirió desde su primer traspaso parecen inalterables: quien lo entrega a otra persona en una despedida es porque la estima (Rey Hazas, 1995: 308) y el objeto sirve de aglutinador de ese afecto. Sin embargo, también se convierte en un objeto que transmite la honra ${ }^{9}$. Es muy interesante ver cómo don Jorge parte de viaje junto con su hermano don Fernando y su lacayo Galindo, a quienes sus amantes también dan una prueba de su afecto y estima, que lógicamente no tendrá más recorrido en la acción que en este momento puntual. Así, don Fernando recibe una cinta de doña Ana y Galindo una toquilla y unas longanizas de parte de Esperanza, siendo el caso de los criados el habitual contrapunto cómico de los amos, en este caso relacionado con una de sus necesidades más perentorias y recurrentes: la comida.

El segundo acto cierra el círculo cuando don Jorge llega a la corte y está en presencia del Veinticuatro y del rey Fernando, primer poseedor de la joya, que se da cuenta de que lleva puesto el anillo que le habia regalado al protagonista de la obra, y tal refleja Lope en acotación para que el actor sepa que tiene que marcar muy bien el momento en que el monarca ve el objeto en la mano de quien no debe. El rey pide explicaciones al Veinticuatro y este le hace saber que se lo entregó a su esposa, con lo que el monarca se contenta porque el matrimonio une a las dos personas en una sola, aunque le recomienda que le pida el anillo a su mujer para que se lo devuelva y confirme o refute las sospechas de infidelidad que, ahora, empiezan a

${ }^{9}$ Oleza (1986: 260). Nos parece interesante la interpretación de Zuckerman-Ingber (1979: 63), para quien el anillo es símbolo del honor, que es otorgado como recompensa por el valor. Quien posee el anillo también posee el honor de otro personaje, pero al cabo de un tiempo se convierte en un objeto que pasa por distintas manos y los personajes pierden tanto la sortija como la honra. 
atormentarle. Así, el anillo cumple una función fundamental: conforma la anagnórisis que revelará la verdad decisiva de la comedia al protagonista para que resuelva el conflicto de la pérdida de su honra.

Más allá de estos objetos, que guardan un significado especial, lo cierto es que la mitad del tercer acto contiene una sucesión de malos presagios que suceden a los comendadores en unos trescientos cincuenta versos. Costa Palacios y Abad Gómez (1981: 133) ya destacaron su importancia para el desarrollo del clímax de la pieza. Acaecen cuando el Veinticuatro ya es conocedor de la verdad y justo antes de que se produzca la venganza. De hecho, cuando el protagonista les da agua, lo hace porque están asustados por dichos agüeros tan negativos. Así, los comendadores don Jorge y don Fernando se quejan de una espada atascada que no puede ser desenvainada (v. 2308), hablan sobre un espejo que se rompe (v. 2316), sobre un animal herido (v. 2325), departen acerca de un mal sueño (v. 2329), de un grito que escucha uno de ellos (v. 2331) y de unos aullidos (v. 2335), uno se cae al suelo (v. 2439), también vuelca el vaso de agua que se asociaba a la honra del Veinticuatro (v. 2450), uno es acusado por don Luis de ser un mal amigo por no haberle defendido en un incidente anterior (v. 2641) y relatan la muerte de un caballo (v. 2656). Los comendadores están muy asustados porque no comprenden la naturaleza y significado de esos presagios (Armas, 1992: 768), y todo este proceso culmina, podríamos decir, con el golpe que se escucha en el verso 2719 , que bien puede ser el de la escala del Veinticuatro cuando entra en su casa y se dispone a tomar venganza, confirmándose los malos augurios.

\section{Conclusiones}

En Los comendadores de Córdoba se desarrolla fundamentalmente el tema de la honra del protagonista. Es una de las primeras comedias de Lope en las que el código del honor está casi completado, y como tal es imposible disociarlo de lo que hemos denominado las relaciones entre los personajes, que no pueden calificarse siempre de amorosas, pero sí de admiración vasallática, aprecio personal o amor de pareja, según el caso. Unas y otras presentan características positivas y negativas, e incluso evolucionan con el transcurso de la acción, muy especialmente la representada por el vínculo matrimonial entre el Veinticuatro y doña Beatriz, que le es infiel a su marido. Es precisamente el reconocimiento de esa infidelidad y la consiguiente pérdida de la honra por parte del protagonista lo que supone el principio del desenlace de la obra, por lo que los procedimientos de anagnórisis están en la base de la resolución del conflicto principal, que será climática. Pero es que, además, en la pieza se observa un marcado simbolismo como recurso intimamente relacionado con las causas de las agniciones que se 
producen, sobre a través del anillo, como se ha explicado. En consecuencia, y siguiendo una estructura amplificativa, determinados elementos concretos y simbólicos poseen un significado tan preciso que permiten la aparición de anagnórisis que revelan la verdad al único personaje que no la conocía, para que el Veinticuatro, así, construya ese desenlace climático que intenta recuperar, a través de un cruento proceso, la honra que había perdido por la actitud de otros agonistas y que conforma el núcleo temático de esta comedia de Lope de Vega.

\section{Bibliografia}

Álvarez Sellers, M.R. (1997): "Los Comendadores de Córdoba (1598). Lope de Vega". En Análisis y evolución de la tragedia amorosa en el Siglo de Oro: la tragedia amorosa. Kassel, Reichenberger, vol. ii, págs. 579-606.

Armas, F.A. de (1992): «La estructura mítica de Los comendadores de Córdoba». En Vilanova, A. (ed.): Actas del x Congreso de la Asociación Internacional de Hispanistas. Barcelona, ppu, págs. 763-771.

Cañas Murillo, J. (1995): Honor y honra en el primer Lope de Vega: las comedias del destierro. Cáceres, Universidad de Extremadura.

Castro, A. y Rennert, H.A. (1969): Vida de Lope de Vega (1562-1635). Salamanca, Anaya.

Costa Palacios, A. y Abad Gómez, M. (1981): «La Leyenda de los Comendadores de Córdoba, posible fuente de "Teatro de Horror" en dos Comedias de Lope de Vega». En Criado del Val, M. (ed.): Lope de Vega y los orígenes del teatro español. Actas del i Congreso Internacional sobre Lope de Vega. Madrid, EDI-6, págs. 125-142.

Ebersole, A.V. (1983): «El tema del adulterio en Los Comendadores de Córdoba». En González, A. et al. (eds.): Estudios sobre el Siglo de Oro en homenaje a Raymond R. MacCurdy. Albuquerque-Madrid, University of New Mexico-Cátedra, págs. 59-65.

Escudero Baztán, J.M. (2014): "Violencia y género en Los comendadores de Córdoba de Lope de Vega”. Romance Quarterly, 61.1, págs. 5-16.

Fernández, J. (1986): «Los comendadores de Córdoba: ¿Un caso de honor recobrado?». Bulletin of the Comediantes, 38.1, págs. 55-62.

García Rey, V. (1928): «Escrituras inéditas de Lope de Vega Carpio». Revista de la Biblioteca, Archivo y Museo, v.xviii, págs. 198-205.

Laplana, J.E. (1999): «Dos notas a Los comendadores de Córdoba de Lope de Vega». Anuario Lope de Vega, v, págs. 197-198.

Larson, D.R. (1971): "Los comendadores de Córdoba: An Early Honor Play». En Kossoff, D.A. y Amor y Vázquez, J. (eds.): Homenaje a William L. Fichter: Estudios sobre el teatro antiguo hispánico y otros ensayos. Madrid, Castalia, págs. 399-412.

López Martín, I. (2014): "El dolor y la muerte en las comedias de Lope de Vega». Transitions. Journal of Franco-Iberian Studies, 10, págs. 41-63.

Menéndez Pelayo, M. (1949): Estudios sobre el teatro de Lope de Vega. E. Sánchez Reyes (ed.). Madrid, csic. 
Morley, S.G. y Bruerton, C. (1947): «Addenda to The Chronology of Lope de Vega's Comedias". Hispanic Review, xv.1, págs. 49-71.

Oleza, J. (1986): «La propuesta teatral del primer Lope de Vega». En Canet Vallés, J.L. (coord.): Teatro y prácticas escénicas. ii La Comedia. Londres, Tamesis, págs. 251-308.

Rey Hazas, A. (1991): "Los comendadores de Córdoba: hacia la fórmula definitiva de la tragicomedia barroca". Anuario de Estudios Filológicos, xiv, págs. 413-425.

- (1995): "Los comendadores de Córdoba en el proceso de elaboración de la tragicomedia barroca». En Canavaggio, J. (ed.): La Comedia. Madrid, Casa de Velázquez, págs. 303-319.

Rozas, J.M. (1976): Significado y doctrina del Arte nuevo de Lope de Vega. Madrid, Sociedad General Española de Librería.

Stroud, M.D. (1981): "Los Comendadores de Córdoba: Realidad, Manierismo y el Barroco". En Criado del Val, M. (ed.): Lope de Vega y los orígenes del teatro español. Actas del i Congreso Internacional sobre Lope de Vega. Madrid, EDI-6, págs. 425-429.

Vega Carpio, L.F. de (1993-1994): Rimas. F.B. Pedraza Jiménez (ed.). Cuenca, Universidad de Castilla-La Mancha.

- (1998): Los comendadores de Córdoba. J.E. Laplana Gil (ed.). En Blecua, A. y Serés, G. (dirs.) e Iriso, S. (coord.): Comedias de Lope de Vega. Parte ii. Lérida, Milenio, vol. ii, págs. 1023-1174.

Zuckerman-Ingber, A. (1979): «Honor Reconsidered: Los Comendadores de Córdoba». Journal of Hispanic Philology, 4.1, págs. 59-75. 
